\title{
DUAS NOVAS ESPECIES DE CALLICHROMATINI NEOTROPICAIS (COLEOPTERA, CERAMBYCIDAE, CERAMBYCINAE)
}

\author{
SERGIO A. FRAGOSO ${ }^{+}$\& MIGUEL A. MONNE ${ }^{++}$ \\ Museu Nacional, Quinta da Boa Vista, 20942 Rio de Janeiro, RJ, Brasil
}

\begin{abstract}
Two new species of neotropical Callichromatini (Coleoptera, Cerambycidae, Cerambycinae) Cnemidochroma lopesi, sp. n. and Xenochroma seabrai, sp. n., from Brazil are described.
\end{abstract}

Key words: Cnemidochroma - Xenochroma - Cerambycidae - Coleoptera

\section{Cnemidochroma lopesi sp. $\mathrm{n}$.}

(Figs. 1, A \& B, 2 A)

Macho - Tegumento enegrecido com reflexos cúpreos, mais notáveis nos élitros. Face dorsal revestida de tomento preto com reflexos cúpreos, mais compacto no pronoto do que nos élitros; face ventral com pubescência acinzentada esparsa. Antenas pretas; pernas enegrecidas, com reflexos purpúreos.

Cabeça submetálica; fronte cerca de uma vez e meia mais longa que larga, região mediana subde primida, com finas estrias transversais. Genas glabras e pontuadas, os pontos se tornando seriados e estriados inferiormente aos lobos oculares. Antenas atingindo aproximadamente o início do quinto distal dos élitros; escapo pontuado, mais brilhante que o restante dos artículos, desprovido de fosseta basal. Face ventral do artículo III com setas pretas, longas, nitidamente mais densas que nos artículos IV e V; VI-XI sem setas. Artículo III cerca de uma vez e meia mais longo que o VI; IV e V subiguais; VI-X sutilmente decrescentes; XI apenas mais longo que o $\mathrm{X}$.

Protórax com grande tubérculo lateral rombo, precedido de tuberosidade arredondada. Pronoto com depressão anterior transversa distinta; disco elevado e subplano, posteriormente com área transversa deprimida. Superfície do pronoto com pilosidade densa, aveludada; lados do protórax e prosterno subglabros.

\footnotetext{
+EMBRAPA, comissionado no Museu Nacional.

${ }^{++}$Bolsista do Conselho Nacional de Desenvolvimento Científico e Tecnológico.
}

Escutelo sulcado apenas na região apical. Élitros subparalelos, com três costas longitudinais insinuadas, convergentes para a extremidade. Äpices arredondados. Superfície sem linhas metálicas dorsais. Epipleuras com faixa longitudinal de pubescência mais escura, mais notável na metade basal.

Prosterno com rugas superficiais, látero-posteriores às cavidades coxais; com carena mediana sutil, anterior ao processo intercoxal. Processo mesosternal densamente pubescente, sem sulcos evidentes. Metasterno com pontos providos de setas curtas, grossas e pretas. Abdômen muito finamente pontuado; região subapical de cada segmento com setas semelhantes às do metasterno. Ultimo urosternito ( $\left.8^{\circ}\right)$ emarginado no ápice, último urotergito (89) truncado na extremidade (Fig. 2A).

Metatíbias achatadas, com cerca de uma vez e meia a maior largura do metafêmur.

Fêmea - Antenas alcançando aproximadamente o meio dos élitros; artículo XI uma vez e meia mais longo do que o $\mathrm{X}$; último urosternito (7!) truncado.

$\begin{array}{lrr}\text { Dimensões, em mm: } & \text { Macho } & \text { Fêmea } \\ \text { Comprimento total } & 28,0 & 26,0 \\ \text { Comprimento do protórax } & 5,0 & 4,7 \\ \text { Maior largura do protórax } & 6,0 & 6,0 \\ \text { Comprimento do élitro } & 21,0 & 19,8 \\ \text { Largura umeral } & 8,0 & 8,0\end{array}$

Holótipo macho, BRASIL, Mato Grosso: Município de Vila Bela da Santíssima Trindade, BR 364, km 558, ii.1978, B. Silva col. 

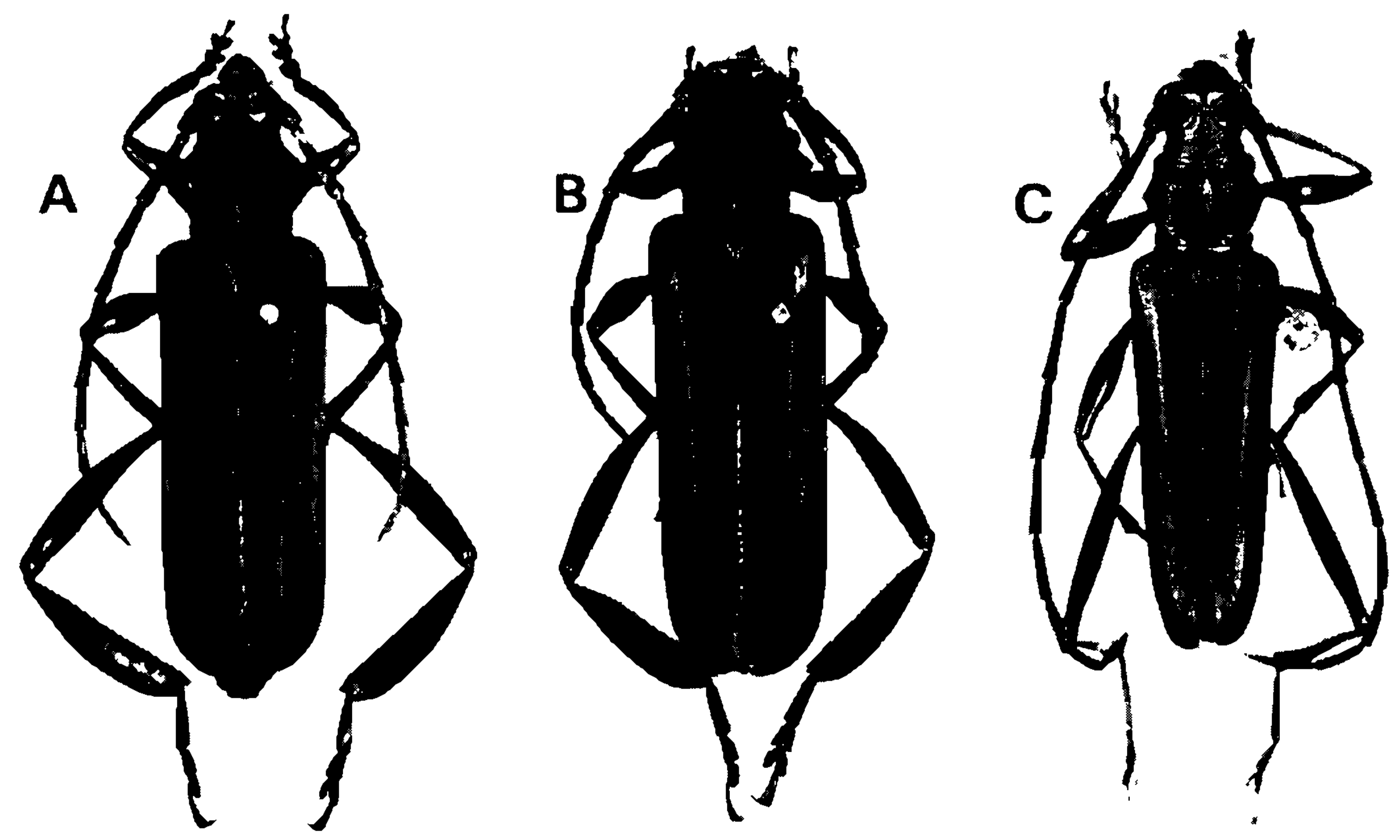

Fig. 1 A: Cnemidochroma lopesi sp. n., holótipo macho. Fig. 1 B: idem, parátipo fêmea. Fig. 1C: Xenochroma seabrai sp. n., holótipo macho.

Parátipo fêmea, BRASIL, Distrito Federal: Brasília, iv.1962, A. B. Guimarães col. (ex. col. Fragoso).

Holótipo macho e parátipo fêmea na coleção do Museu Nacional, Rio de Janeiro.

\section{COMENTÄRIOS}

Cnemidochroma lopesi sp. n., pertence ao conjunto de espécies distingüivel pelo protórax e élitros revestidos de densa pubescência preta, que abrange (Demets, 1974: 92) C. phyliopus (Guérin-Ménéville, 1844) e C. ohausi (Schmidt, 1924), ambas distribuídas na floresta atlântica.

Separa-se de $C$. phyllopus, pelas tíbias posteriores aproximadamente uma vez e meia mais largas que a largura máxima dos metafêmures. Em C. phyllopus, as metatíbias são pelo menos duas vezes mais largas que a largura máxima dos metafêmures.

Distingue-se de $C$. ohausi, a) escapo com lados subretos e sem entumescimento subapical, b) pronoto com a região pós-mediana plana e sem depressão látero-posterior acentuada, c) sulco do escutelo restrito à metade distal e d) élitros sem estreita linha longitudinal mediana subglabra com brilho metálico. Em $C$. ohausi, a) o escapo é entumescido subapicalmente e os lados são retos, b) a região pós-mediana do pronoto é mais elevada e a depressão látero-posterior acentuada, c) o escutelo é sulcado da base ao ápice e d) os élitros apresentam estreita banda longitudinal mediana subglabra, com brilho metálico.

Cnemidochroma lopesi sp. n., é assim nomeada em homenagem ao Dr. Hugo Souza Lo. pes, professor e amigo, pelo transcurso de seu octagésimo aniversário e do sexagésimo ano de atividades cient íficas.

\section{Xenochroma seabrai sp. $\mathrm{n}$.}

(Figs. 1C e 2B)

Macho - Tegumento predominantemente verde metálico; cada élitro dividido em duas faixas longitudinais, a intema verde metálica, não atinge o ápice, a externa, vermelho-cobreado, contorna o élitro do úmero até a extremidade Antenas e pernas pretas. Face ventral verde metálica, com pubescência cinzento-prateada, exceto os urosternitos sétimo e oitavo, que são testáceos.

Cabeça com a fronte de bordos paralelos. Área entre os tubérculos anteníferos mais densamente pontuada do que a fronte. Antenas alcançando o ápice dos élitros aproximadamente na extremidade distal do artículo VIII. Esca- 
po subglabro, com pontos esparsos no lado externo, mais densos no interno. Face ventral dos artículos III e IV com setas longas, mais densas que nos artículos V.VI; artículo III cerca de uma vez e meia mais longo que o IV; artículo XI aproximadamente uma vez e meia mais longo do que o $\mathrm{X}$.

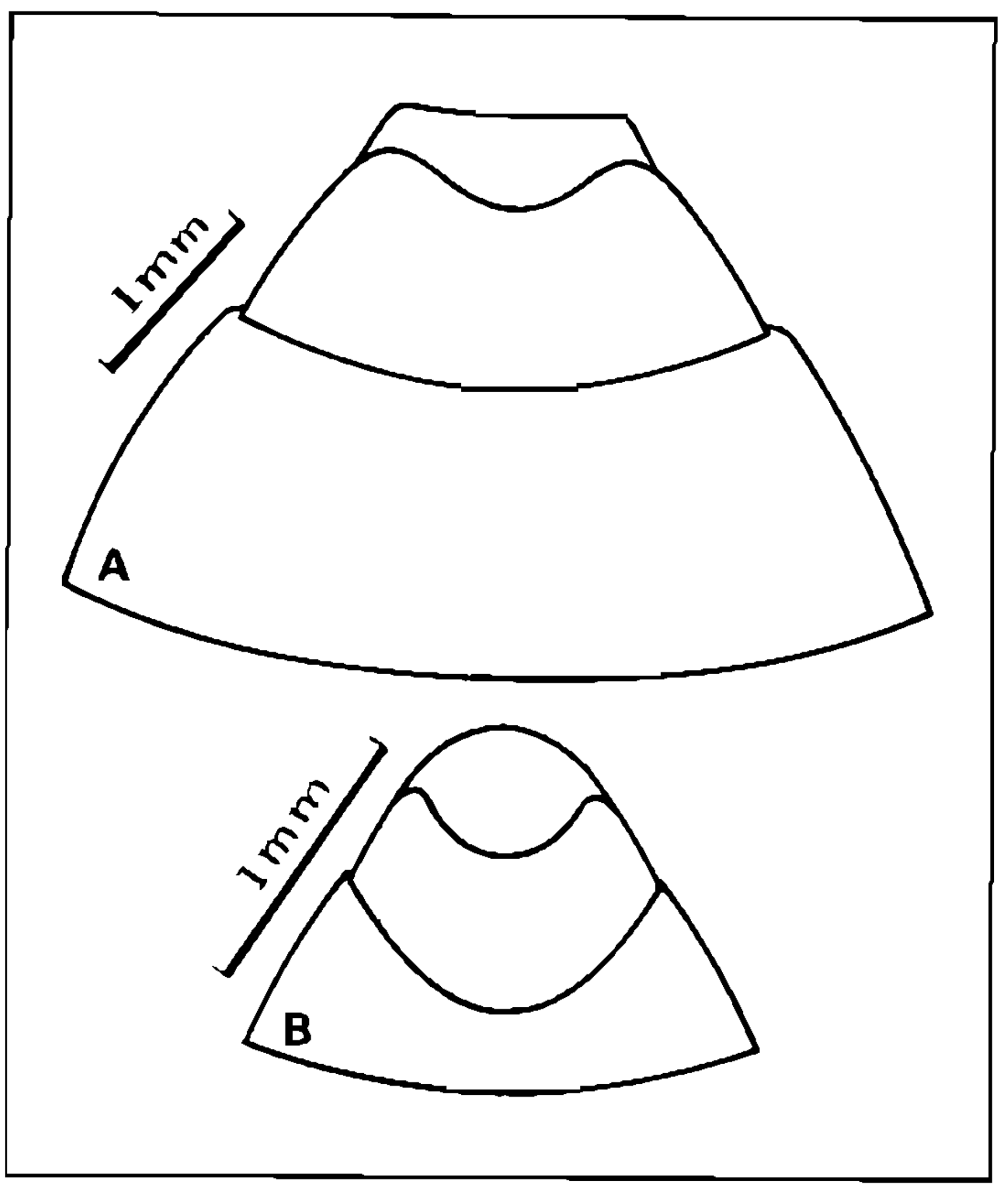

Fig. $2 \div$ aspecto ventral diagramático do ápice do abdômen: A. Cnemidochroma lopesi sp. n., macho. B. Xenochroma seabrai sp. n., macho.

Protórax com tubérculos laterais medianos, diminutos e arredondados, com tumescência látero-anterior. Pronoto subplano, com as regiōes laterais rugosas, contrastando com o disco pontuado (exceto numa estreita linha longitudinal mediana, composta de fragmentos de rugas). Pubescência muito curta e esparsa, confinada ao disco.

Escutelo pontuado, com pilosidade esparsa e decumbente. Élitros planos, ligeiramente convergentes para as extremidades. Ápices arredondados. Pontuaçāo densa e uniforme; pubescência restrita a escassas setas longas no sexto basal.

Prosterno com o bordo anterior castanho e glabro, o restante da superfície verde metálico, com pubescência acinzentada. Processo proster- nal ligeiramente tumescente no bordo posterior. Mesosterno com processo subplano, largo, revestido com pilosidade grisea decumbente. Metasterno densamente pontuado, com pubescência decumbente. Pontuação do abdômen igual à do metasterno. Ápices dos urosternitos sétimo e oitavo (Fig. 2B) fortemente emarginados; oitavo urotergito com bordo apical arredon. dado.

Pernas com trocanteres providos de tufos de pêlos acinzentados na parte inferior. Pro e mesofêmures clavados, com curta carena apical sublateral, mais nítida nos fêmures médios; metafêmures gradualmente engrossados para o ápice. Metatíbias sinuosas, ligeiramente alargadas para a extremidade distal.

Fêmea - Antenas atingindo o ápice dos élitros aproximadamente na extremidade distal do artículo $X$; sétimo urostemito castanho, com ligeiros reflexos metálicos, truncado no ápice.

$\begin{array}{lcc}\text { Dimensões, em mm: } & \text { Macho } & \text { Fêmea } \\ \text { Comprimento total } & 13,3 & 12,8 \\ \text { Comprimento do protórax } & 2,5 & 2,3 \\ \text { Maior largura do protórax } & 3,0 & 2,9 \\ \text { Comprimento do élitro } & 9,5 & 9,0 \\ \text { Largura umeral } & 3,7 & 3,5\end{array}$

Holótipo macho e dois parátipos, macho e fêmea, BRASIL, Minas Gerais: Pedra Azul, 700 m, xi.1972, C. A. Campos Seabra e F. M. Oliveira col., depositados na coleção do Museu Nacional.

\section{COMENTÁRIOS}

Xenochroma seabrai sp. n., distingue-se de $X$. subpulvereum (Schmidt, 1924) e de $X$. uniforme (Gounelle, 1911), únicas espécies descritas da América do Sul, pelos élitros bicolores e pelas carenas subapicais dos pro e mesofêmures. Em ambas as espécies citadas os élitros são uniformemente verdes e os pro e mesofêmures não são carenados.

Xenochroma azurea Demets, 1976 e X. tibialis Giesbert, 1987, descritas da América Central, são azuis e unicolores e os élitros acham-se revestidos de curto tomento preto aveludado.

Os exemplares de $X$. seabrai sp. n., foram capturados na mesma localidade em que foram 
achadas Chrysoprasis aurigena (Germar, 1824) e $C$. auriventris longipes Aurivillius, 1910, com idêntico padrão de distribuição de cores nos élitros.

\section{REFERËNCIA}

DEMETS, Y., 1974. Notes sur les Callichromatini (Col., Cerambycidae). III. Étude preliminaire du genre Cnemidochroma Schmidt, 1924. Papéis Avulsos Zool., S. Paulo, 28: 91-104. 